\title{
Modelo para formação de parcerias na construção civil
}

\author{
A model for forming partnerships in the construction \\ industry
}

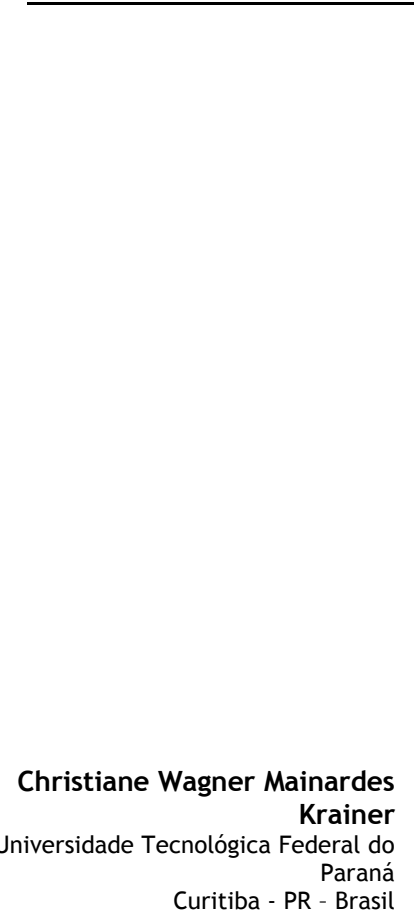

Jefferson Augusto Krainer Universidade Tecnológica Federal do Paraná
Curitiba - PR - Brasil

Ricardo Cataldi Universidade Federal do Rio Grande do Sul

Porto Alegre - RS - Brasil

Alfredo larozinski Neto Universidade Tecnológica Federal do Paraná Curitiba - PR - Brasil

Cezar Augusto Romano Universidade Tecnológica Federal do

Paraná

Curitiba - PR - Brasil

Recebido em 20/05/17 Aceito em 20/09/17

\section{Christiane Wagner Mainardes Krainer Jefferson Augusto Krainer \\ Ricardo Cataldi \\ Alfredo larozinski Neto \\ Cezar Augusto Romano}

\section{Resumo}

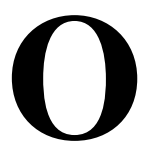

presente artigo tem por objetivo formular um modelo de avaliação da eficiência do relacionamento entre construtoras e fornecedores para a construção de parcerias na cadeia de suprimentos da construção civil. Foram pesquisadas, com adoção do método survey, 100 empresas brasileiras, 50 fornecedoras e 50 construtoras. Os dados foram analisados com a aplicação de técnicas multivariadas (cluster, análise fatorial, correlação de Spearman e regressão linear). O modelo desenvolvido nesta pesquisa explica, por meio da criação de um índice de eficiência composto por três fatores determinantes (confiança, relacionamento de longo prazo e compartilhamento de informações), as características do relacionamento interorganizacional na amostra pesquisada. Serve, portanto, de orientação diretiva para adoção de estratégias de formação de parcerias entre construtoras e fornecedores. Para melhorar os índices de eficiência do relacionamento construtora-fornecedor, os principais processos que precisam ser considerados quando da criação de estratégias de parcerias são: seleção e avaliação de desempenho de fornecedores e realização de reuniões conjuntas.

Palavras-chave: Parceria. Relacionamento interorganizacional. Construtora. Fornecedor. Gestão da cadeia de suprimentos. Construção civil.

\section{Abstract}

The objective of this article is to formulate an evaluation model to measure the effectiveness of a construction company relationship in creating partnerships with the supply chain of the construction industry. A survey was conducted with 100 Brazilian companies (50 suppliers and 50 construction companies) and the collected data was analysed using multivariate techniques such as cluster, factorial analysis, Spearman correlation and linear regression. Through the creation of an efficiency index composed of three determining factors (trust, longterm relationship and information sharing), the model developed in this study explains the characteristics of interorganisational relationships in the sample studied. Hence, this model serves as a guideline for the adoption of strategies to form partnerships between builders and suppliers. To improve the efficiency of the relationship between construction companies and suppliers, the following key processes should be considered when adopting partnership strategies: supplier selection, performance assessment and joint meetings.

Keywords: Partnership. Interorganizational relationship. Construction company. Supplier. Supply chain management. Construction industry. 


\section{Introdução}

A indústria da construção civil caracteriza-se por apresentar uma cadeia produtiva complexa, heterogênea, formada por um conjunto de atividades com graus diferentes de dificuldades, interligados por diversos produtos e processos tecnológicos variados (ISATTO, 2005). Segundo Azambuja e O’Brien (2009), o setor é composto por um sistema de múltiplas empresas de diversos produtos e serviços com inconstante utilização de recursos, ligadas comercialmente, com o fim de realizar um empreendimento, em geral único. Vrijhoef e Koskela (2000) acrescentam que a cadeia de suprimentos da construção civil é:

(a) convergente: os suprimentos convergem para o canteiro de obras;

(b) temporária: as organizações que se formam para a realização de um empreendimento único não costumam perdurar para o empreendimento seguinte e podem assumir uma configuração diferente da anterior; e

(c) make-to-order: cada projeto cria um produto único e com pouca repetição.

As características peculiares do processo produtivo da indústria da construção geram problemas de eficiência na cadeia de suprimentos, como a falta de coordenação e integração entre as variadas faces funcionais envolvidas, principalmente em função da separação entre o projeto e a construção do empreendimento (AZAMBUJA; O’BRIEN, 2009). Akintoye, McIntosh e Fitzgerald (2000) ressaltam que para se operar com todo o potencial da gestão da cadeia de suprimentos do setor faz-se necessário melhorar os elos com fornecedores, subcontratados e especialistas (integração interna). O modo como são assumidos os processos de aquisição e de integração de fornecedores é fundamental para obtenção de resultados positivos, aumento da produtividade e para a redução de custos unitários (VRIJHOEF; KOSKELA, 2000). A cooperação entre empresas impacta no desempenho da cadeia, pois possibilita a realização de ações conjuntas, além de viabilizar a transação de recursos (ISATTO, 2005).

Do que se percebe, a gestão do relacionamento interorganizacional assume papel-chave dentro da cadeia de suprimentos da construção civil. Dentre as estratégias dessa gestão destaca-se a construção de parcerias. Lambert, Emmelhainz e Gardner (1996) conceituam parceria como um relacionamento de negócio fundamentado em confiança mútua, abertura, riscos e recompensas compartilhados que resultam em melhor desempenho e geram vantagem competitiva. A realização de parcerias duradouras promove melhor desempenho da cadeia, evitando a interrupção de abastecimento de materiais, diminuindo o risco de atrasos e multas contratuais, além de tornar a empresa confiável e de qualidade (BANDEIRA; MELLO; MAÇADA, 2009; SANTOS; JUNGLES, 2008). A parceria na cadeia de suprimentos promove flexibilidade organizacional, aumento do fluxo de informações, redução de incertezas, além de propiciar o desenvolvimento de um ambiente de apoio à inovação e ao aprendizado, aumentando a possibilidade de lucro para toda a cadeia do setor da construção civil (BEACH; WEBSTER; CAMPBELL, 2005).

Dessa forma, pesquisas focadas no relacionamento interorganizacional construtoras-fornecedores, como a presente, justificam-se por contribuírem para elaboração de estratégias de formação de parcerias e, por consequência, para o desenvolvimento da cadeia de suprimentos. Nesse contexto, esta pesquisa tem por objetivo formular um modelo de avaliação da eficiência do relacionamento entre construtoras e fornecedores para a construção de parcerias na cadeia de suprimentos da construção civil.

\section{Revisão bibliográfica}

A compreensão dos possíveis mecanismos e estruturas das relações interorganizacionais é de suma importância para a gestão da cadeia de suprimentos da construção civil. Afinal, as relações construtora-fornecedor, tradicionalmente consideradas como adversas e puramente comerciais, têm sido vistas como mais colaborativas e flexíveis, reconhecendo-se que os fornecedores são fontes essenciais para obtenção de vantagem competitiva (BEACH; WEBSTER; CAMPBELL, 2005).

Em razão do impacto positivo que uma melhor gestão de suprimentos causa nas organizações, esta passou por reestruturações e assumiu um novo conceito baseada em atividades estratégicas, em que o foco é dado às ações de negociação de relacionamentos a prazos mais longos, desenvolvimento de fornecedores e redução de custo total (SANTOS; JUNGLES, 2008).

Dentre essas estratégias destaca-se a construção de parcerias. Tuten e Urban (2001) em pesquisa em vários setores industriais, incluindo a construção civil, relacionaram os motivos que levaram as empresas a formarem parcerias, quais sejam: redução de custos, obtenção de vantagem competitiva, melhora dos indicadores de desempenho e aumento da qualidade dos produtos. 
O surgimento do conceito de parceria remonta à década de 1940 nas empresas de manufatura japonesas. De acordo com Dyer e Ouchi (1998), na filosofia japonesa a parceria é vista como um relacionamento exclusivo (ou semiexclusivo) entre comprador e fornecedor tendente a maximizar a eficiência de toda cadeia de valor, tendo como objetivo o aumento da qualidade com redução dos custos totais para ambas as partes. Os autores caracterizam a parceria estilo japonesa da seguinte forma:
(a) relacionamentos de longo prazo;
(b) comunicação frequente;
(c) assistência mútua;
(d) investimentos para customizar instalações, equipamentos e pessoal;

(e) compartilhamento de informações técnicas e dos custos;

(f) construção de confiança entre as organizações;

(g) intercâmbio de funcionários; e

(h) uso de contratos flexíveis com os fornecedores.

O Construction Industry Institute (1991) conceitua parceria como um compromisso de longo prazo entre duas ou mais empresas que visa atingir as finalidades do projeto para potencializar a eficácia dos recursos de cada partícipe. O relacionamento, de acordo com o Instituto, é fundamentado na confiança, comprometimento e objetivos comuns, assim como na compreensão das expectativas e dos valores individuais de cada componente.

A parceria com fornecedores visa alavancar habilidades estratégicas e operacionais de cada participante, auxiliando-os na obtenção de benefícios contínuos e encorajando-os a empreender esforços mútuos para resolução de problemas e para compartilhar a responsabilidade pelo sucesso do produto (LI et al., 2005). Nesse passo, deve-se promover entre os parceiros o comprometimento (motivação mútua), o que pode ser alcançado por meio da construção de uma relação justa, igualitária e com base no "ganhaganha" (BEACH; WEBSTER. CAMPBELL; 2005).

Diversos autores abordam os benefícios da formação de parcerias. Para Cheung et al. (2003) alguns benefícios mútuos são: melhoria da produtividade e dos custos; oportunidade de inovação; compartilhamento dos riscos; e redução dos conflitos. Possíveis benefícios para construtoras e fornecedores decorrentes da construção de parcerias estão relacionados no Quadro 1.

O nível de envolvimento e/ou de relacionamento entre os participantes varia de acordo com o tipo e/ou com o estágio de parceria. O Quadro 2 ilustra três classificações para as parcerias entre clientes e fornecedores.

Os elementos críticos para o sucesso das parcerias foram identificados por diversos autores, conforme apresentado no Quadro 3.

Para uma parceria de sucesso, a confiança é o elemento mais citado pelos autores (Quadro 3). Objetivos comuns, equidade ou igualdade, comunicação eficaz, comprometimento, avaliação de desempenho, equipe integrada e relação de longo prazo são outros elementos destacados pelos autores relacionados no Quadro 3.

Santos e Jungles (2008) apontam três elementoschaves para a formação de parcerias na construção civil: confiança e cooperação, relacionamento de longo prazo e compartilhamento de informações. Quando presentes esses elementos, reforçam os autores, a probabilidade de um resultado positivo, como a ampliação do nível de valor agregado e a redução do desperdício, é maior. De acordo com Li et al. (2012), uma melhor relação compradorfornecedor impacta na melhoria da competitividade das organizações e é influenciada pela comunicação eficaz, confiança e desenvolvimento do fornecedor, fatores que necessitam de compromisso a longo prazo e apoio da alta gerência.

O êxito da parceria está relacionado a um comportamento não oportunista. Confiança é a expectativa de que um parceiro não possua um comportamento oportunista, mesmo sem benefícios de curto prazo e diante da incerteza sobre os proveitos de longo prazo (CHILES; MCMACKIN, 1996). A confiança tem por base a crença de que as partes não agirão em oposição aos interesses em comum e se trata de um valor estratégico quando propicia ganhos mútuos (CHEN; PAULRAJ; LADO, 2004). Purdy e Safayeni (2000) explicam que a confiança permite que fornecedores se envolvam e cooperem no desenvolvimento de empreendimentos do seu comprador, aumentando ainda mais o grau de envolvimento na aliança. 
Quadro 1 - Benefícios na formação de parcerias

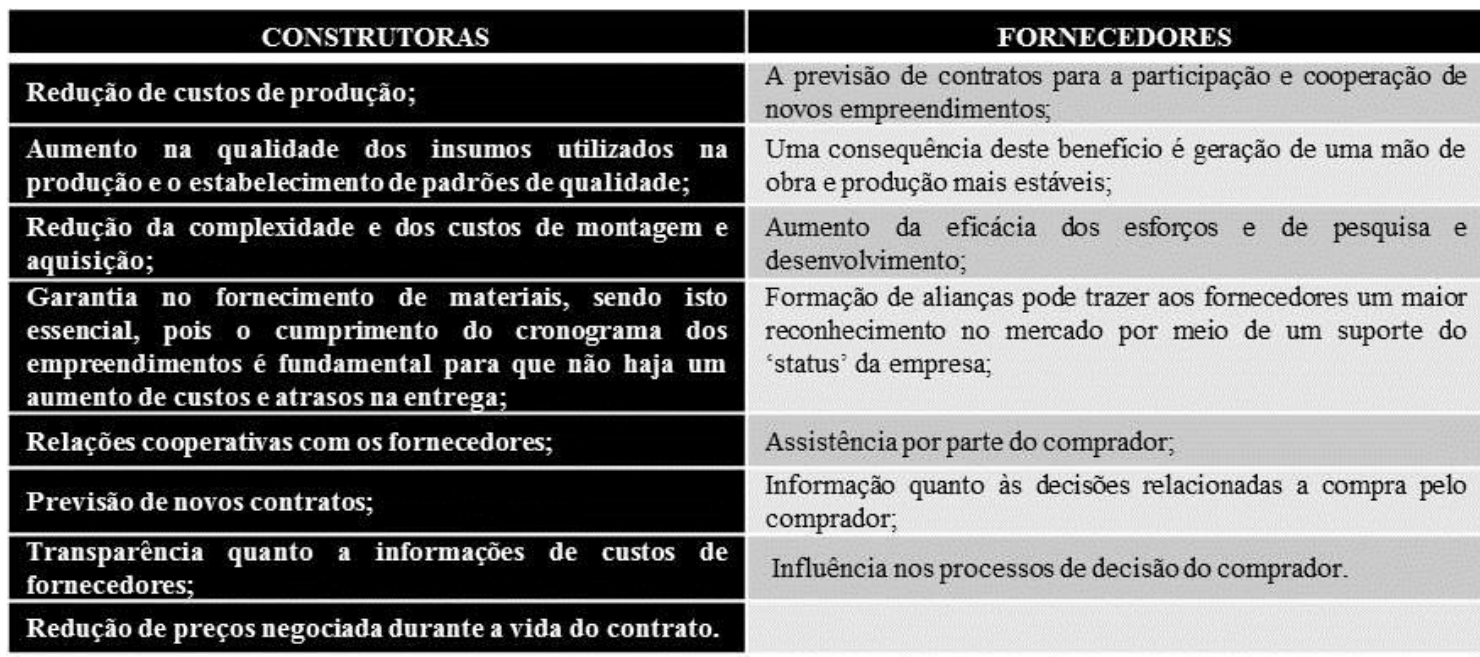

Fonte: adaptado de Lyons, Krachenberg e Henke Junior (1990)

\section{Quadro 2 - Tipos de parcerias clientes $\mathrm{x}$ fornecedores}

\begin{tabular}{|c|c|c|}
\hline Autor (es) & Característica & Tipos de Parceria \\
\hline Merli (1994) & $\begin{array}{l}\text { Três níveis de relacionamento } \\
\text { operacional em razão do grau de } \\
\text { desenvolvimento do que ele } \\
\text { denomina comakership ou rela- } \\
\text { cionamento de parceria, na qual } \\
\text { as ações são tomadas em con- } \\
\text { junto. }\end{array}$ & $\begin{array}{l}\text { Classe III (fornecedor comum): negociações com base em } \\
\text { especificações de qualidade mínima; estoques de segurança; preços; } \\
\text { lotes individuais a curto prazo; e inspeções sistemáticas dos supri- } \\
\text { mentos. } \\
\text { Classe II (fornecedor "integrado" ou comakership "operacional"): } \\
\text { qualidade garantida e autocertificada com base em critérios preesta- } \\
\text { belecidos; melhora sistemática da qualidade e dos preços dos } \\
\text { produtos fornecidos; reabastecimento automático e sem estoque } \\
\text { intermediário; ajuste dos preços baseado em critérios concordados; } \\
\text { fornecimentos frequentes em pequenos lotes para pedidos "em } \\
\text { aberto"; relacionamento de longo prazo e com revisões periódicas; } \\
\text { responsabilidades globais pelos produtos fornecidos; ausência de } \\
\text { inspeção de recebimento; e consultoria e treinamento dos } \\
\text { fornecedores. } \\
\text { Classe I (fornecedor comaker ou parceiro): comakership global com } \\
\text { características de parceria; atividades operacionais da classe II; } \\
\text { cooperação no projeto de novos produtos/tecnologias; investimen- } \\
\text { tos comuns em planejamento e desenvolvimento e em realizações } \\
\text { tecnológicas; e intercâmbio contínuo de informação sobre os pro- } \\
\text { cessos e produtos. }\end{array}$ \\
\hline $\begin{array}{l}\text { Lambert, } \\
\text { Emmelhainz e } \\
\text { Gardner } \\
\text { (1996) }\end{array}$ & $\begin{array}{l}\text { Três tipos de parceria conforme } \\
\text { grau de envolvimento do for- } \\
\text { necedor com a empresa. }\end{array}$ & $\begin{array}{l}\text { Tipo I: as empresas se posicionam como parceiras e, com limitações, } \\
\text { gerenciam as atividades e o planejamento. A parceria tem um foco } \\
\text { de curto prazo e abrange apenas uma área ou setor da organização. } \\
\text { Tipo II: as empresas avançam além do gerenciamento das atividades, } \\
\text { partindo para a integração. A parceria é de longo prazo. Abrange } \\
\text { várias áreas e setores das organizações. } \\
\text { Tipo III: as empresas possuem um nível significativo de integração } \\
\text { operacional. Cada empresa percebe a outra como uma extensão de } \\
\text { sua própria empresa. Não há um prazo para a parceria terminar. }\end{array}$ \\
\hline $\begin{array}{l}\text { Li et al. } \\
\text { (2001) }\end{array}$ & Quatro estágios de parceria. & $\begin{array}{l}\text { Estágio } 1 \text { (competitivo): empresas parceiras estão em contato entre } \\
\text { si em um único ponto, não há busca de comprometimento, há alto } \\
\text { grau de confrontação. A parceria existe apenas para atender a } \\
\text { exigências de contrato. É o caso mais comum em parcerias na } \\
\text { construção civil. } \\
\text { Estágio } 2 \text { (orientado para a cooperação): há uma maior comunicação } \\
\text { e interação entre as partes devido à mudança de formato das orga- } \\
\text { nizações para se adaptarem ao empreendimento. } \\
\text { Estágio } 3 \text { (integrado): intensificam-se ainda mais as comunicações e } \\
\text { interações, havendo troca de conhecimentos e de recursos entre os } \\
\text { parceiros; } \\
\text { Estágio } 4 \text { (cooperação estratégica): forma-se uma aliança estratégica } \\
\text { que promove uma comunicação efetiva, troca de conhecimentos, } \\
\text { acesso a tecnologia e a recursos. Cria-se uma parceria baseada na } \\
\text { confiança e no comprometimento. }\end{array}$ \\
\hline
\end{tabular}


Quadro 3 - Elementos críticos de sucesso para parcerias na construção civil

\begin{tabular}{|l|}
\hline \multicolumn{1}{|c|}{ Fatores } \\
\hline Confiança \\
\hline Objetivos comuns \\
\hline Equidade ou igualdade \\
\hline Comunicação eficaz \\
\hline Comprometimento \\
\hline Avaliação de desempenho \\
\hline Equipe integrada \\
\hline Relação de longo prazo \\
\hline Resolução de problemas/disputas \\
\hline Relação "ganha-ganha" \\
\hline Recompensas e benefícios mútuos \\
\hline Risco compartilhado \\
\hline Investimentos/incentivos \\
\hline
\end{tabular}

\begin{tabular}{|c|c|c|c|c|c|c|c|c|c|c|}
\hline 1 & 2 & 3 & 4 & 5 & 6 & 7 & 8 & 9 & 10 & Frequência \\
\hline $\mathrm{x}$ & $x$ & $\mathrm{x}$ & $\mathrm{x}$ & $x$ & $x$ & $x$ & $\mathrm{x}$ & $x$ & $x$ & 10 \\
\hline \multirow[t]{3}{*}{$x$} & $x$ & $x$ & $x$ & & $x$ & $x$ & $x$ & $x$ & $x$ & 9 \\
\hline & $x$ & $\mathrm{x}$ & & $\mathrm{x}$ & $\mathrm{x}$ & & $\mathrm{x}$ & $\mathrm{x}$ & & 6 \\
\hline & & & $x$ & $x$ & & $x$ & $x$ & $x$ & $\mathrm{x}$ & 6 \\
\hline \multirow[t]{5}{*}{$\mathrm{x}$} & & & $x$ & $x$ & $\mathrm{x}$ & & $\mathrm{x}$ & $\mathrm{x}$ & & 6 \\
\hline & & $\mathrm{x}$ & $x$ & & $x$ & & $x$ & & $x$ & 5 \\
\hline & & & $\mathrm{x}$ & $\mathrm{x}$ & $\mathrm{x}$ & $\mathrm{x}$ & & $\mathrm{x}$ & $\mathrm{x}$ & 6 \\
\hline & $\mathrm{x}$ & & $\mathrm{x}$ & & & $\mathrm{x}$ & & $\mathrm{x}$ & $x$ & 5 \\
\hline & & & & & $\mathrm{x}$ & & & $\mathrm{x}$ & & 2 \\
\hline \multirow[t]{4}{*}{$\mathrm{x}$} & & & & & $\mathrm{x}$ & & & & & 2 \\
\hline & $\mathrm{x}$ & & & $\mathrm{x}$ & & & & & & 2 \\
\hline & $\mathrm{x}$ & & & & $\mathrm{x}$ & & & & & 2 \\
\hline & $\mathrm{x}$ & & & & & & & $\mathrm{x}$ & & 2 \\
\hline
\end{tabular}

Nota: Legenda:
(1) Cook e Hancher (1990);
(2) Construction Industry Institute (1991);
(3) Hellard (1995);
(4) Black, Akintoye e Fitzgerald (2000);
(5) Scott (2001);
(6) Kumaraswamy e Matthews (2001)
(7) Cheng e Li (2002);
(8) Ng et al. (2002);
(9) Tang, Duffield e Young (2006); e
(10) Chen e Chen (2007).

O desenvolvimento da confiança tem reflexos nas atividades de cooperação. $\mathrm{Na}$ gestão do relacionamento com fornecedores o comprometimento e a confiança promovem maior cooperação, reduzem conflitos e melhoram a tomada de decisão (CHEN; PAULRAJ; LADO, 2004). Johnston et al. (2004) advertem que a confiança por si só não determina a cooperação, porém ganhar a confiança do fornecedor é um elemento-chave para que este participe de atividades de cooperação. $\mathrm{O}$ comportamento cooperativo, complementam os autores, está associado à responsabilidade mútua na resolução de problemas e ao planejamento e acordos flexíveis para enfrentar eventualidades.

Selnes (1998) desenvolveu um modelo teórico de confiança e satisfação com o objetivo de melhorar o relacionamento entre comprador e fornecedor (Figura 1). De acordo com o modelo, a confiança é impactada pela competência e pelas comunicações honestas e oportunas, sendo que a comunicação, o compromisso e a resolução de conflitos refletem na satisfação da relação comprador-fornecedor. A satisfação do comprador-fornecedor também reflete na confiança e quanto maior a confiança melhor a relação e, consequentemente, mais contínua a parceria.

O elemento relacionamento de longo prazo também garante maior confiança; é normalmente estabelecido por meio de contratos. Os contratos, além de consolidarem a confiança, permitem uma visão estratégica compartilhada e maior colaboração entre as empresas, pois um bom comprador trabalhará junto com o seu fornecedor, e vice-versa, para que ambos permaneçam fortes financeiramente (PURDY; SAFAYENI, 2000). Para Cook e Hancher (1990), parceiros que se comprometem em uma relação de longo prazo estão mais propensos a construírem um relacionamento de entendimento mútuo dos objetivos, de forma a atingirem suas metas e vantagens competitivas. Segundo Akintoye, McIntosh e Fitzgerald (2000), os relacionamentos de longo prazo entre construtoras e fornecedores podem proporcionar ganhos de produtividade ao setor.

Santos e Jungles (2008) aduzem que as relações de longo prazo permitem a elaboração de uma visão estratégica compartilhada e são estabelecidas por acerto de contratos de longo prazo, com renovação automática conforme o atingimento de resultados esperados. Os autores reforçam que o funcionamento conjunto e prolongado (parcerias duradouras) dos agentes que compõem a cadeia garante a plena e correta execução das atividades do canteiro de obras, assegurando, assim, que não haja interrupção de abastecimento de materiais, diminuindo a incidência de atrasos e multas contratuais e elevando a qualidade da organização, além de melhorar a imagem desta perante o mercado. 
Figura 1 - Modelo teórico de confiança

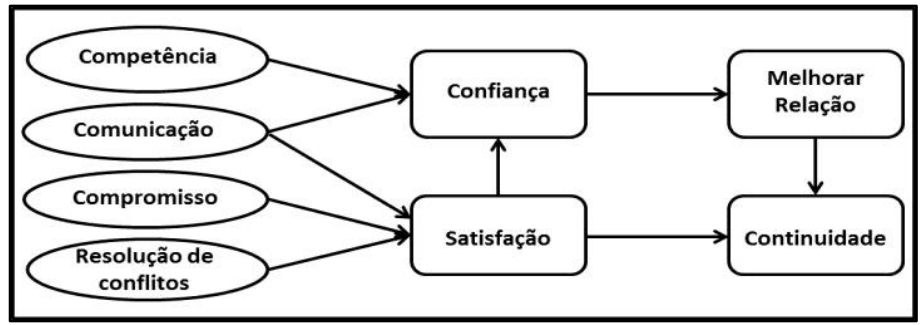

Fonte: Selnes (1998).

O terceiro elemento-chave para a formação de parcerias é o compartilhamento de informações, que pode se dar desde as especificações de produtos e projetos, planejamento e programações de compras, até o acesso total a uma base de dados dos clientes e/ou dos fornecedores. Tal elemento impulsiona a integração interorganizacional, na medida em que pode viabilizar a transferência de know-how e a realização de treinamentos e reuniões entre compradores e fornecedores (PURDY; SAFAYENI, 2000). O compartilhamento das informações pode, inclusive, ser utilizado como fonte de vantagem competitiva, na media em que o uso eficaz de uma informação pode gerar diferenciação e competitividade na cadeia de suprimentos (LI et al., 2005). A comunicação eficiente é imprescindível para melhorar a probabilidade de um relacionamento "ganhaganha", o que é essencial para a equidade da relação de parceria (LAZAR, 2000).

O compartilhamento de informação de maneira franca, aberta, respeitosa e com confiança é a chave para uma comunicação eficiente e, consequentemente, para uma parceria de sucesso (NG et al., 2002). Beach, Webster e Campbell (2005) salientam que a comunicação em uma parceria é crucial para a compreensão das expectativas, atitudes e limitações das partes envolvidas. A comunicação contínua e de via dupla é um fator importante na redução de incertezas no comportamento dos parceiros (SUH; KWON, 2006). Segundo Ojala e Hallikas (2006), para reduzir a incerteza e risco de investimento, a informação deve ser transparente e compartilhada entre os parceiros.

A literatura de logística costuma considerar que os relacionamentos dentro das cadeias são baseados apenas na cooperação e na confiança, mas estudos recentes apontam a relevância do poder e da dominação como "[...] constructos nas relações em cadeias de suprimentos [...]" (BANDEIRA; MELLO; MACADA, 2009, p. 377). Para Bachmann (2001), a confiança e o poder são os principais mecanismos de coordenação das relações interorganizacionais. Venselaar, Gruis e Verhoeven
(2015) acrescentam que devido às características da indústria da construção civil (fragmentação, baixa repetição e empreendimentos únicos), a formação de parcerias, ainda que assimétricas, incrementa a eficiência e aumenta a lucratividade das empresas. Mesmo nos casos em que há assimetria na relação, a parceria poder ser duradoura, uma vez que, ainda que a troca de benefícios seja desigual e os riscos desproporcionais, o membro mais fraco pode se beneficiar da relação (BANDEIRA; MELLO; MAÇADA, 2009).

Vale ressaltar que em um projeto de construção não pode faltar a união dos recursos e dos esforços dos partícipes, em função da imprescindibilidade do trabalho em equipe, com o fim de desenvolver a cooperação, comunicação aberta e a resolução de problemas em conjunto e que promove, também, algo não muito comum no setor, a interdependência (CHEUNG et al., 2003).

\section{Método}

Para a concretização do objetivo deste trabalho foi realizada uma pesquisa exploratória, descritiva, com abordagem quantitativa e de corte transversal (em um dado ponto no tempo). O método survey foi adotado como procedimento para levantamento de dados primários. O desenvolvimento do método survey e os procedimentos de análise dos dados são descritos a seguir.

\section{Procedimento baseado no método survey}

Optou-se pelo método survey em razão de a coleta de dados da amostra envolver um número elevado de indivíduos (mais de 30).

O método survey foi delineado em três etapas:

(a) identificação das informações a serem geradas e definição das variáveis;

(b) delimitação da população-alvo e da amostra; e

(c) elaboração do instrumento de coleta de dados. 
O processo da survey se inicia a partir do estabelecimento de informações que se deseja obter sobre o tema pesquisado. Para a realização desta pesquisa foram adotadas variáveis tendentes a descrever e avaliar o relacionamento das construtoras com seus fornecedores de insumos (vide variáveis V1 a V20 no Quadro 5). Portanto, as variáveis utilizadas na elaboração do instrumento de coleta de dados estão relacionadas, principalmente, à confiança, ao relacionamento de longo prazo e ao compartilhamento de informações, conforme destacado por autores como Santos e Jungles (2008), Bandeira, Mello e Macada (2009), Li et al. (2012) e nos Quadro 1, 2 e 3 .

A população-alvo definida foi de empresas brasileiras de construção civil, sendo metade de construtoras (50) e a outra metade de fornecedores. Em razão da dificuldade de retorno do apelo da pesquisa, optou-se por uma amostragem não probabilística por conveniência, selecionando-se membros acessíveis da população. Dessa forma, a amostra, na presente pesquisa, não pode ser considerada como representativa da população e, consequentemente, extrapolações e generalizações não são possíveis.

Como instrumento de coleta de dados foi aplicado um questionário, o qual foi subdividido em duas partes:

(a) perfil da organização e do entrevistado; e

(b) características do relacionamento construtorafornecedor (Quadro 5).

Para mensurar as variáveis quantitativas utilizou-se a escala de diferencial semântico, com 7 categorias de resposta. Essa escala, destinada a aquilatar atitudes, contempla um par de adjetivos ou frases antônimas distribuídas em um intervalo de intensidade, em que o respondente deve escolher o grau que melhor representa sua opinião.

Realizou-se, inicialmente, um pré-teste com uma amostra de três construtoras e três fornecedores. Nesse primeiro momento, o questionário foi administrado pessoalmente pelos pesquisadores, o que permitiu avaliar a provável exatidão e coerência das respostas. Durante a aplicação do questionário, foi possível esclarecer dúvidas e definir conceitos eventualmente não bem compreendidos, minimizando-se, por consequência, possíveis erros. O pré-teste promoveu alguns ajustes necessários no questionário.

No presente estudo os dados foram coletados por meio de um questionário autoadministrado, enviado por $e$-mail e gerenciado com o auxílio da ferramenta Google Docs.

No projeto de pesquisa, a meta mínima de amostragem prevista foi de 100 empresas participantes, sendo 50 construtoras e 50 fornecedores. Com a finalidade de garantir a confiabilidade dos dados coletados, contatou-se, inicialmente, os diretores das construtoras e das fornecedoras. Com a aprovação destes e indicação dos possíveis respondentes, o questionário foi apresentado e disponibilizado para resposta. A coleta de dados perdurou por seis meses, de fevereiro a novembro de 2016.

O Quadro 4 sumariza as principais características da amostra.

\section{Procedimentos de análise dos dados}

Os dados foram analisados com o emprego de técnicas de estatística descritiva e inferencial. A estatística descritiva foi utilizada para descrever e resumir os dados por meio das seguintes medidas: coeficiente de variação e quantis (33 e 66). As técnicas aplicadas para análise da estatística inferencial foram: teste de hipótese, clusters, análise fatorial, correlação de Spearman e análise de regressão múltipla. Os dados foram tratados com o auxílio dos programas Statistical Package for the Social Sciences (SPSS) e $R$ Project for Statistical Computing (R).

Os resultados obtidos com a estatística descritiva foram utilizados como referência para a análise das distribuições amostrais das variáveis. Dessa forma, quanto mais próximos estiverem os quantis menor serão as assimetrias caudais, isto é, mais concentrados estarão os dados em torno da média. Essa característica também pode ser visualizada pelo desvio padrão. A média indica um nível qualitativo de satisfação do relacionamento construtora-fornecedor; quanto mais elevada melhor será a relação. Por outro lado, o coeficiente de variação indica qual a posição relativa do desvio padrão em relação à média, sendo um índice calculado a fim de se identificar a qualidade geral do relacionamento na cadeia de fornecedores.

Adicionalmente, testes de hipóteses foram aplicados para avaliar a estrutura global dos dados e verificar a existência ou não de diferença entre as médias para as respostas de construtoras e de fornecedores. Nesses testes foram ponderadas as diferenças das somas totais das respostas (qualidade total do relacionamento construtora-fornecedor) e dos coeficientes de variação (qualidade relativa do relacionamento). 
Quadro 4 - Perfil da amostra

\begin{tabular}{|c|c|c|c|}
\hline \multicolumn{2}{|r|}{ Perfil da Empresa Construtora } & \multicolumn{2}{|r|}{ Perfil da Indústria Fornecedora } \\
\hline Características & $\%$ & Características & $\%$ \\
\hline Localidade & $\begin{array}{l}\text { Curitiba - } 64 \% \\
\text { Pinhais - } 6 \% \\
\text { São José dos Pinhais - 4\% } \\
\text { Campo Grande - } 8 \% \\
\text { Bombinhas, Cascavel - 2\% } \\
\text { Campina Grande, Itapema, Londrina - 2\% } \\
\text { Passos, Brasília - 2\% } \\
\text { Rondonópolis, São Paulo - 2\% }\end{array}$ & Localidade & $\begin{array}{l}\text { Curitiba - } 46 \% \\
\text { Londrina - } 8 \% \text {, Pinhais - 4\%, Maringá - 2\% } \\
\text { Almirante Tamandaré, Colombo - 2\% } \\
\text { Campo Largo, Campo Magro - 2\% } \\
\text { Piraquara, São José dos Pinhais - 2\% } \\
\text { Tijucas, Joinville - 6\%, Caçador, Bombinhas - 2\% } \\
\text { Tambaú, Criciúma - 2\% } \\
\text { São Paulo - 4\%, Porto Alegre, Taboão da Serra - 2\% }\end{array}$ \\
\hline Fundação & $\begin{array}{l}\text { Até } 5 \text { anos - } 12 \% \\
\text { Entre } 5 \text { e } 10 \text { anos - } 16 \% \\
\text { Entre } 10 \text { e } 20 \text { anos - } 34 \% \\
\text { Mais de } 20 \text { anos - } 32 \% \\
\text { Não responderam - } 6 \%\end{array}$ & Fundação & $\begin{array}{l}\text { Até } 5 \text { anos }-12 \% \\
\text { Entre } 5 \text { e } 10 \text { anos }-22 \% \\
\text { Entre } 10 \text { e } 20 \text { anos - } 28 \% \\
\text { Mais de } 20 \text { anos - } 36 \% \\
\text { Não responderam }-2 \%\end{array}$ \\
\hline Tipo de administração & $\begin{array}{l}\text { Familiares }-38 \% \\
\text { Profissionais }-40 \% \\
\text { Mista }-20 \% \\
\text { Outro }-2 \%\end{array}$ & Tipo de administração & $\begin{array}{l}\text { Familiares - } 28 \% \\
\text { Profissionais }-58 \% \\
\text { Mista }-14 \% \\
\text { Outro }-0 \%\end{array}$ \\
\hline Tipo de constituição & $\begin{array}{l}\text { Sociedade Limitada - } 76 \% \\
\text { Capital Misto - } 8 \% \\
\text { SA Capital Aberto - } 4 \% \\
\text { SA Capital Fechado - } 4 \% \\
\text { Outro - } 6 \% \\
\text { Não responderam - } 2 \%\end{array}$ & Tipo de constituição & $\begin{array}{l}\text { Sociedade Limitada - } 70 \% \\
\text { Capital Misto - } 0 \% \\
\text { SA Capital Aberto - } 6 \% \\
\text { SA Capital Fechado - } 24 \% \\
\text { Outro - } 0 \% \\
\text { Não responderam - } 0 \%\end{array}$ \\
\hline $\begin{array}{l}\text { Número de } \\
\text { funcionários }\end{array}$ & $\begin{array}{l}\text { Até } 19 \text { funcionários - } 52 \% \\
\text { Entre } 20 \text { e } 99 \text { funcionários - } 22 \% \\
\text { Entre } 100 \text { e } 499 \text { funcionários - } 8 \% \\
\text { Mais de } 500 \text { funcionários - } 6 \% \\
\text { Não responderam - } 12 \%\end{array}$ & $\begin{array}{l}\text { Número de } \\
\text { funcionários }\end{array}$ & $\begin{array}{l}\text { Até } 19 \text { funcionários - } 12 \% \\
\text { Entre } 20 \text { e } 99 \text { funcionários - } 32 \% \\
\text { Entre } 100 \text { e } 499 \text { funcionários - } 20 \% \\
\text { Mais de } 500 \text { funcionários - } 26 \% \\
\text { Não responderam - } 10 \%\end{array}$ \\
\hline Certificação & $\begin{array}{l}\text { Nenhuma - } 54 \% \\
\text { PBPQ-H - } 24 \% \\
\text { ISO } 9001-28 \% \\
\text { ISO } 14000-2 \% \\
\text { Outros - } 2 \% \\
\text { Não responderam - 4\% }\end{array}$ & Certificação & $\begin{array}{l}\text { Nenhuma - 58\% } \\
\text { PBPQ-H - } 6 \% \\
\text { ISO } 9001-28 \% \\
\text { ISO } 14000-10 \% \\
\text { Outros- } 10 \% \\
\text { Não responderam - } 0 \%\end{array}$ \\
\hline
\end{tabular}

Na sequência, a estrutura de agrupamento dos dados coletados foi analisada, com a finalidade de validar o tratamento e a análise desses dados de forma conjunta (identificação da estrutura composta pelas respostas dos construtores e dos fornecedores). Utilizou-se, para tanto, da análise de clusters, método $K$-means, que, ao contrário dos métodos hierárquicos, produzem agrupamentos simples (não relacionados).

Nessa análise foram pré-definidos três grupos, em virtude da composição do questionário e da relação qualitativa do relacionamento construtorafornecedor. O questionário foi elaborado com o intuito de avaliar três fatores principais de captação de informação sobre o relacionamento construtorafornecedor: confiança, relacionamento de longo prazo e compartilhamento de informações entre os parceiros. Assim, o objetivo inicial da análise de agrupamentos foi identificar os grupos de questões para validar a estrutura de dados a analisar.

Formados os grupos, estes foram classificados em três níveis distintos de integração. Como o volume de interatividade entre as construtoras e fornecedores precisa ser coeso, optou-se pela classificação em níveis alto, médio e baixo, a partir da posição relativa da observação na amostra com base no coeficiente de variação. A definição dos níveis, considerando os quantis amostrais foi:

(a) nível baixo: observações abaixo do $33^{\circ}$ quantil;

(b) nível médio: observações entre o $34^{\circ}$ e o $66^{\circ}$; e

(c) nível alto: observações acima do $66^{\circ}$, considerando os percentis amostrais.

A qualificação global das empresas permitiu inferir, com base em um score padrão relativo, a distribuição de probabilidade associada à soma dos valores. Assim, a inferência possibilita discutir, por categoria, se existe uma correlação entre as posições que são mais coesas e com melhor relacionamento com aquelas que são menos coesas e com menor relacionamento.

O resultado obtido na análise cluster indicou a possibilidade do tratamento e análise conjunta dos 
dados coletados (construtoras e fornecedores). Em continuidade, procedeu-se à análise fatorial, por meio do método de formação de componentes principais. Esse método possibilita gerar variáveis aleatórias que estejam alinhadas ao grupo de questões relativas à qualidade, ordenando-as de acordo com a capacidade que o conjunto de variáveis tem de explicar a variância amostral.

A avaliação da adequação amostral e o desenvolvimento da análise fatorial observaram os seguintes procedimentos: análise da matriz de correlações, teste KMO, teste de esfericidade de Bartlett, matriz anti-imagem e comunalidades. Ato contínuo, foram analisados o número de fatores retidos (critério de Kaiser), a matriz de componentes rotacionados e a rotação varimax. Por fim, foram obtidos os escores fatoriais utilizados nas análises de correção e de regressão.

Com esses resultados, estruturou-se um conjunto de três componentes. Essa estratégia analítica permitiu reduzir o número de variáveis necessárias para um modelo preditivo e isolar efeitos desnecessários, antes de prosseguir para a regressão linear. Assim, a adoção de três componentes resultou em uma formatação mais enxuta que captou exatamente os três fatores determinantes na análise de relacionamento construtora-fornecedor para o setor da construção civil: a confiança nos fornecedores/construtores, o relacionamento de longo prazo e o compartilhamento de informações.

Para validar a estrutura do modelo de regressão, fezse uma análise de correlação entre as variáveis pelo coeficiente de Spearman ( $\rho)$, o qual usa, em vez do valor observado, apenas a ordem das observações. Os componentes principais precisam ter baixa correlação entre si e alta correlação com as variáveis que representam, a fim de se ter um bom modelo.

$\mathrm{Na}$ interpretação dos resultados, o coeficiente de correlação Spearman $(\rho)$ varia de -1 a 1 . O valor diz respeito à força da relação entre as variáveis e o sinal indica a direção positiva ou negativa do relacionamento. O grau de correlação entre as variáveis em cada análise foi destacado a partir da variação do coeficiente $(\rho)$ definido por Hair Junior et al. (2005), com inclusão de cores para cada associação (Figura 2).

Uma correlação perfeita (-1 ou 1) demonstra que o escore de uma variável pode ser determinado ao se conhecer o escore da outra. Em contrapartida, uma correlação de valor zero revela que não há relação linear entre as variáveis.

Como os três fatores obtidos são relevantes na explicação do coeficiente de variação, então os componentes principais são bem estruturados e de fato explicam o relacionamento da empresa com seus parceiros, possibilitando inferir sobre a qualidade da gestão da cadeia de fornecedores a partir deles.

A análise de regressão linear foi realizada entre os fatores e o coeficiente de variação das variáveis. O coeficiente de variação é utilizado para avaliar a desigualdade entre os entrevistados no que tange ao relacionamento entre construtoras e fornecedores. Dessa forma, capta a dispersão na relação das construtoras com os fornecedores na amostra utilizada e representa a eficiência relativa de cada empresa com relação à amostra.

A parametrização do modelo linear segue a Equação 1:

$\delta=\alpha+\beta_{1} c_{1}+\beta_{2} c_{2}+\beta_{3} c_{3}+\varepsilon$

Eq. 1

Com isso, o coeficiente de variação $\delta$ é explicado pelos componentes principais $\mathrm{C}_{1}, \mathrm{C}_{2}$ e $\mathrm{C}_{3}$ em uma parametrização linear. Por fim, foram realizados os testes de validação do modelo, por meio da normalidade dos resíduos, média, consistência de variância, capacidade explanatória e existência de heterocedasticidade, multicolinearidade $\mathrm{e}$ endogeneidade.

\section{Análise dos resultados}

Nesta seção é apresentada a análise dos resultados obtidos a partir da estratégia metodológica adotada. $O$ estudo inicia-se pela análise descritiva do conjunto de dados, resumidos no Quadro 5.

Importante destacar que as medidas descritivas servem como uma visualização da eficiência do relacionamento entre construtoras e fornecedores. A Figura 3 retrata as distribuições entre as somas das respostas (medida global do relacionamento construtora-fornecedor) e o coeficiente de variação, isto é, o posicionamento relativo dos construtores e fornecedores.

As diferenças e similitudes na estrutura das respostas foram avaliadas por meio de testes de hipóteses (Tabela 1).

Vale ressaltar, inicialmente, que os testes de hipóteses (Tabela 1) foram validados para 95 observações (empresas); cinco delas, por terem retornado valores nulos, foram descartadas.

Observa-se (Tabela 1) que os valores dos coeficientes de variação (fornecedores e construtoras) seguem uma estrutura muito similar. Por outro lado, no tocante à soma total das respostas, os fornecedores costumam dar notas maiores ao relacionamento com as construtoras do que estas o dão com relação a seus fornecedores (diferença significativa ao nível de 5\%), apontando assimetria no relacionamento. Os resultados 
indicam que, considerando-se a soma total das respostas, os grupos são distintos, impedindo a análise como base de dados única. Portanto, diante da similaridade estrutural dos dados, a análise dos grupos é mais indicada a partir dos coeficientes de variação.

Figura 2 - Representação do coeficiente de correlação

\begin{tabular}{|c|c|c|}
\hline \multicolumn{3}{|c|}{ REGRAS PRÁTICAS SOBRE O VALOR DO COEFICIENTE DE CORRELAÇÃO } \\
\hline VARIAÇÃO DO COEFICIENTE & FORÇA DE ASSOCIAÇÃO & COR \\
\hline $\pm 0,91- \pm 1,00$ & Muito forte & \\
$\pm 0,71- \pm 0,90$ & Alta & \\
$\pm 0,41- \pm 0,70$ & Moderada & \\
$\pm 0,21- \pm 0,40$ & Pequena, mas definida & \\
$\pm 0,01- \pm 0,20$ & Leve, quase imperceptivel & \\
\hline
\end{tabular}

Fonte: adaptado de Hair Junior et al. (2005).

\section{Quadro 5 - Medidas de tendência para o questionário aplicado}

\begin{tabular}{|c|c|c|c|}
\hline Variável & \begin{tabular}{|c|}
$\begin{array}{c}\text { Coeficiente } \\
\text { de } \\
\text { Variação }\end{array}$ \\
\end{tabular} & $\begin{array}{c}\text { Quantil } \\
33\end{array}$ & $\begin{array}{c}\text { Quantil } \\
66\end{array}$ \\
\hline $\begin{array}{l}\text { V1 - Qual o grau de comprometimento do fornecedor na participação e contribuição do ciclo de } \\
\text { desenvolvimento dos produtos da construtora? }\end{array}$ & 0,28 & 5 & 6 \\
\hline V2 - Há relacionamento operacional com os seus fomecedores/construtora? & 0,41 & 3 & 5 \\
\hline V3 - Qual o nível de confiança da empresa em relação a seus fornecedores/construtora? & 0,15 & 6 & 7 \\
\hline V4 - Qual a expectativa de que os seus fornecedores/construtora cumpram com o que foi combinado? & 0,15 & 6 & 7 \\
\hline V5 - A relação entre a empresa e os fornecedores/construtora é duradoura? & 0,19 & 6 & 7 \\
\hline V6 - Há renovação automática de contrato de fornecimento? & 0,52 & 4 & 6 \\
\hline $\begin{array}{l}\text { V7 - Há previsão de novos contratos com os seus atuais fornecedores/principais clientes (construtora)? } \\
\text { (fornecimento para novos empreendimentos) }\end{array}$ & 0,21 & 5 & 6 \\
\hline $\begin{array}{l}\text { V8 - Os seus fornecedores/construtora incentivam e investem no desenvolvimento de novas } \\
\text { tecnologias? }\end{array}$ & 0,31 & 4 & 6 \\
\hline V9 - A empresa tem acesso à formação de custos dos produtos de seus fornecedores/construtora? & 0,73 & 1 & 3 \\
\hline V10 - A construtora pressiona seus fornecedores para um aumento da qualidade? & 0,42 & 4 & 6 \\
\hline $\begin{array}{l}\text { V11 - Como a empresa se percebe no que diz respeito ao poder de barganha que tem sobre seus } \\
\text { fornecedores/construtoras? }\end{array}$ & 0,30 & 4 & 5 \\
\hline V12 - O fornecedor oferece uma politica de preço diferenciada para a construtora? & 0,24 & 5 & 6 \\
\hline V13 - Seus fornecedores/construtora interferem nos programas de produção? & 0,58 & 2 & 4 \\
\hline $\begin{array}{l}\text { V14 - A empresa celebra acordos de exclusividade de fornecimento nos seus empreendimentos/nos } \\
\text { empreendimentos de seus clientes? }\end{array}$ & 0,78 & 1 & 3 \\
\hline $\begin{array}{l}\text { V15 - A empresa dispõe de fornecedores/construtoras que representam igual ou mais de } 50 \% \text { dos } \\
\text { custos de fornecimento da empresa? }\end{array}$ & 0,63 & 2 & 5 \\
\hline $\begin{array}{l}\text { V16 - A construtora exige de seus fornecedores certificação de qualidade de seus produtos e/ou } \\
\text { processos? }\end{array}$ & 0,39 & 4 & 5 \\
\hline V17 - Os fornecedores têm autonomia para a entrega de materiais sem pedidos? & 0,89 & 1 & 2 \\
\hline V18 - O fornecedor participa de reuniões com o corpo técnico o o setor de suprimentos da construtora? & 0,53 & 3 & 5 \\
\hline V19 - A construtora realiza processo seletivo para escolha de seus fornecedores? & 0,44 & 3 & 5 \\
\hline V20 - A construtora realiza processo de avaliação de desempenho de seus fornecedore & 0,38 & 4 & 6 \\
\hline
\end{tabular}


Figura 3 - Posição das construtoras e fornecedores

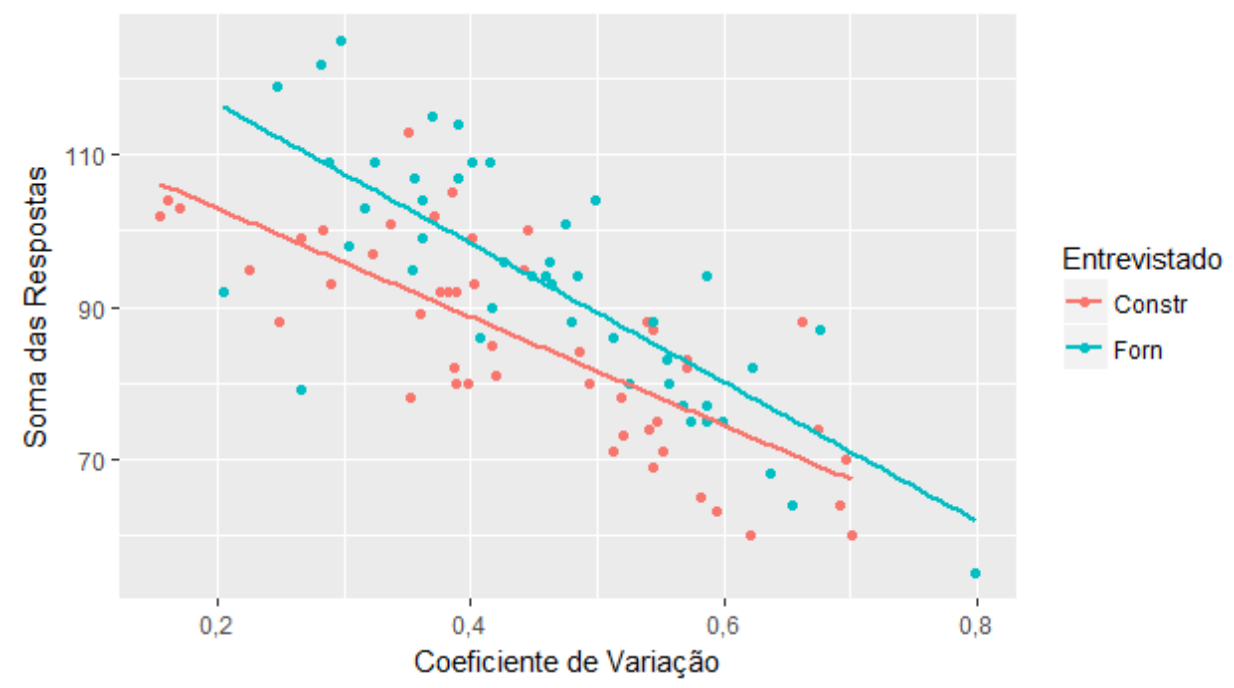

Tabela 1 - Testes de hipóteses

\begin{tabular}{l|c|c}
\hline \multicolumn{3}{c}{ Testes de Hipóteses } \\
\hline \multicolumn{1}{c|}{ Variável } & $\begin{array}{c}\text { Coeficiente de } \\
\text { Variação }\end{array}$ & $\begin{array}{c}\text { Soma das } \\
\text { Respostas }\end{array}$ \\
\hline Formecedores & 0,46 & 93,26 \\
Construtoras & 0,44 & 85,52 \\
\hline $95 \%$ - Intervalo & $-0,07$ & $-13,65$ \\
$95 \%+$ Intervalo & 0,04 & $-1,83$ \\
\hline Observações & 95 & 95 \\
Estatística t & $-0,40$ & $-2,61$ \\
GL (Graus de Liberdade) & 92,89 & 86,33 \\
P-Valor & 0,69 & 0,01 \\
Resultado & Iguais & Diferente \\
\hline
\end{tabular}

Em continuidade, os dados foram estruturados de acordo com as posições relativas do coeficiente de variação de cada respondente com relação aos quantis 33 e 66, formando clusters. Foram identificadas duas características importantes: a assimetria dos dados, indicada pela quantidade de observações em cada cluster e a qualidade do relacionamento, indicada pela quantidade de elementos no cluster de qualidade alta. $\mathrm{Na}$ formação dos clusters foram consideradas 95 observações (5 foram descartadas). A Tabela 2 resume os resultados obtidos.

A estrutura dos clusters indica que as observações com posição média de relacionamento se dividem entre os três clusters, com participação bastante elevada no segundo cluster. Os clusters com participação média e alta estão mais distribuídos, sugerindo que a estrutura de relacionamento das construtoras e fornecedores é heterogênea, no sentido de não se ter uma concentração de clusters com características estruturais em torno de valores mais homogêneos. Para visualizar este fenômeno e compará-lo à distribuição entre fornecedores e construtoras, utiliza-se a Figura 4.

Analisando-se conjuntamente as Figuras 3 e 4 é possível identificar que o cluster $K_{2}$, que corresponde àquele com nível de relacionamento alto, concentra mais construtoras, enquanto $\mathrm{o}$ cluster $K_{3}$, com relacionamento médio, concentra maior quantidade de fornecedores. Isso é reflexo da diferença global da amostra e evidencia que as construtoras são, em geral, mais satisfeitas com seus fornecedores do que estes em relação àquelas. A diferença dos relacionamentos retratada na dispersão de dados, por sua vez, pode ser explicada pelo maior poder de barganha por parte das construtoras, as quais, por consequência, estruturam relações em conformidade com o ritmo de suas atividades e que melhor atendam as suas necessidades.

Com a finalidade de identificar os principais componentes que caracterizam o relacionamento construtora-fornecedor realizou-se a análise fatorial por meio da redução do número de variáveis. O 
objetivo foi trabalhar com os três componentes referentes ao relacionamento entre os construtores e fornecedores definidos nesta pesquisa (confiança, relacionamentos de longo prazo e o compartilhamento de informação).

A análise fatorial identificou, inicialmente, um conjunto de oito componentes principais. Entretanto, a variável V7 teve um grau de significância menor que 0,5 . Assim, a análise foi refeita, desconsiderando-se, dessa vez, a variável V7. Nessa nova análise nenhuma variável retornou com significância menor que 0,5 . Fixou-se, então, o número de componentes em três (predeterminação) e repetiu-se a análise. Nesse caso, as variáveis V6 e V8 a V17 tiveram significância menor que 0,5 e foram descartadas. Por fim, obteve-se um conjunto de oito variáveis distribuídas em três fatores principais (Tabela 3).

Neste estudo, os três componentes conseguem explicar $72 \%$ da variância total das questões avaliadas, possibilitando a sua aplicação como medidas para entender a eficiência da cadeia de suprimentos da construção civil (Tabela 4).

Os componentes principais determinados pela análise fatorial retratam os três fatores principais de captação de informação sobre o relacionamento construtora-fornecedor: confiança entre as partes, relacionamento de longo prazo e o compartilhamento de informações entre os parceiros.

O primeiro fator $(\mathrm{C} 1)$ abrange as variáveis $18,19 \mathrm{e}$ 20 que se referem ao tempo de relacionamento, logo corresponde a "relacionamento de longo prazo". Esse componente possibilita inferir sobre a formação de clusters operacionais estratégicos dentro do mercado.

O segundo fator (C2) é composto pelas variáveis 3 , 4 e 5 e diz respeito à "confiança entre as partes", pois engloba questões associadas ao nível de confiança e à qualidade e durabilidade do relacionamento.

O terceiro fator (C3) abarca as variáveis 1, 2 e 18 (comprometimento, integração e iteratividade), o que se traduz em "compartilhamento de informações". Esse fator fornece indícios, precipuamente, no tocante à comunicação entre as partes, à interligação dos negócios e à unicidade da estrutura.

Tabela 2 - Clusters formados pelo coeficiente de variação

\begin{tabular}{|c|c|c|c|}
\hline Cluster $(\boldsymbol{K})$ & $\boldsymbol{\delta}<\boldsymbol{Q}_{\mathbf{3 3}}$ & $\boldsymbol{Q}_{\mathbf{3 4}}<\boldsymbol{\delta}<\boldsymbol{Q}_{\mathbf{6 6}}$ & $\boldsymbol{Q}_{\mathbf{6 7}}<\boldsymbol{\delta}$ \\
\hline $\boldsymbol{K}_{\mathbf{1}}$ & 18 & 1 & 0 \\
\hline $\boldsymbol{K}_{\mathbf{2}}$ & 4 & 9 & 29 \\
\hline $\boldsymbol{K}_{\mathbf{3}}$ & 10 & 21 & 3 \\
\hline
\end{tabular}

Figura 4 - Posição dos clusters

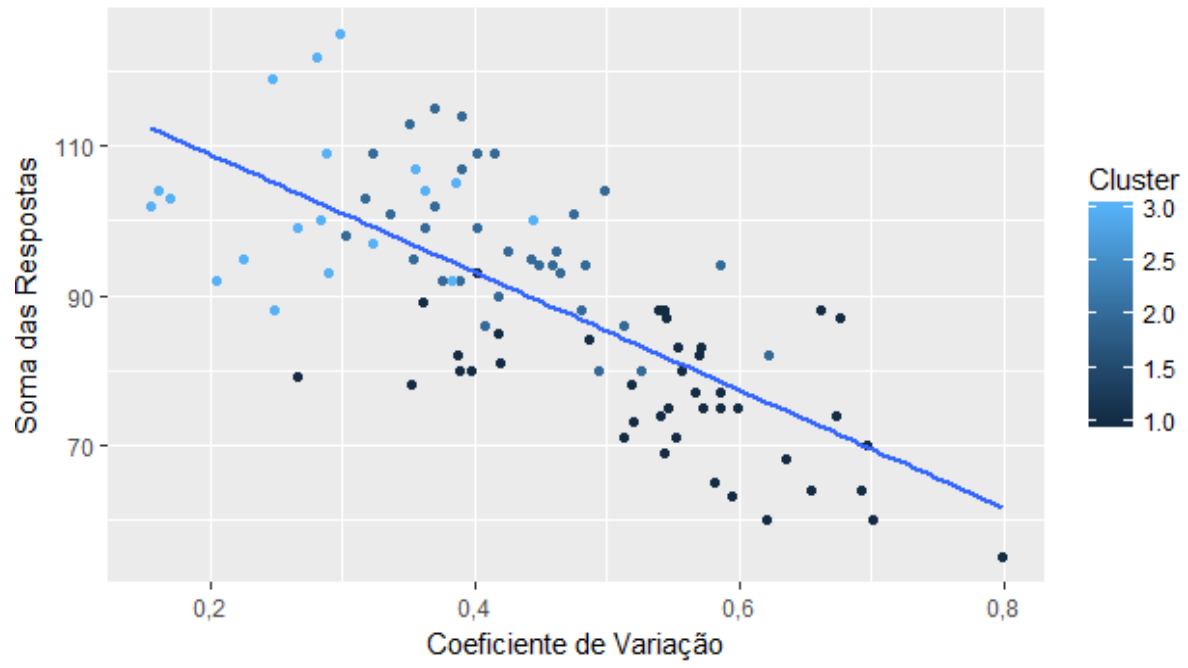


Tabela 3 - Resultado da seleção de componentes

\begin{tabular}{c|c|c|c}
\hline \multirow{2}{*}{$\begin{array}{c}\text { Resultado da Seleção } \\
\text { de Componentes }\end{array}$} & \multicolumn{3}{|c}{ Componente Principal } \\
\cline { 2 - 4 } V19 & $\mathbf{1}$ & $\mathbf{2}$ & $\mathbf{3}$ \\
\hline V20 & 0,820 & & \\
V18 & 0,736 & & 0,579 \\
V3 & & 0,863 & \\
V5 & & 0,789 & \\
V4 & & 0,559 & \\
V1 & & & 0,882 \\
V2 & & & 0,769 \\
\hline
\end{tabular}

Tabela 4 - Total da variância explicada pelos componentes

\begin{tabular}{c|r|r|r|r|r|r}
\hline \multirow{2}{*}{ Componente } & \multicolumn{3}{|c|}{ Autovalores Iniciais } & \multicolumn{3}{c}{ Carga } \\
\cline { 2 - 7 } & Total & \% da Variância & Acumulada \% & Total & \% da Variância & Acumulada \% \\
\hline $\mathbf{1}$ & 3,017 & 37,715 & 37,715 & 2,196 & 27,452 & 27,452 \\
$\mathbf{2}$ & 1,758 & 21,972 & 59,688 & 1,799 & 22,492 & 49,944 \\
$\mathbf{3}$ &, 987 & 12,337 & 72,025 & 1,766 & 22,081 & 72,025 \\
$\mathbf{4}$ &, 736 & 9,197 & 81,222 & & \\
$\mathbf{5}$ &, 490 & 6,122 & 87,345 & & & \\
$\mathbf{6}$ &, 450 & 5,619 & 92,964 & & & \\
$\mathbf{7}$ &, 297 & 3,717 & 96,681 & & & \\
$\mathbf{8}$ &, 266 & 3,319 & 100,000 & & & \\
\end{tabular}

Por fim, tratou-se o conjunto dos três componentes por meio de análise de correlação entre as variáveis pelos coeficientes de Spearman. A Tabela 5 traz a matriz de correlação entre componentes e variáveis.

Nota-se (Tabela 5) que os componentes têm baixa correlação entre si e alta correlação com as variáveis que os representam. Há alta associação do componente 1 (C1) com as variáveis V18, V19 e $\mathrm{V} 20$, que representam o compartilhamento de informações; alta associação do $\mathrm{C} 2$ com as variáveis V3 e V5, e moderada associação com a variável V4, que representam a durabilidade do relacionamento; e alta associação do $\mathrm{C} 3$ com as variáveis V1 e V2, e moderada associação com a variável V18, que representam o nível de confiança entre as partes. Essas correlações, portanto, validam a construção de um bom modelo de regressão linear.

Assim, para avaliar de forma explicativa o relacionamento entre construtoras e fornecedores, adotou-se como estratégia final deste estudo a formação de um modelo de regressão linear (Tabela 6). Os testes Breuch-Pagan, Durbin-Watson, VIF (variance inflation factors) e NCV (non-constant variance) resultaram negativos para a presença de heterocedasticidade, endogeneidade multicolinearidade.
Os resultados indicam a variação dos parâmetros em virtude da composição do índice de eficiência, isto é, quanto menor o $\delta$, maior a eficiência do relacionamento entre construtora e fornecedor. Assim, as relações negativas entre os componentes são explicadas pela estrutura de formação do índice de eficiência na gestão do relacionamento construtora-fornecedor. A parametrização do modelo linear corresponde à Equação 2:

$$
\delta=0,450-0,037 C_{1}-0,053 C_{2}-0,018 C_{3}+\epsilon
$$

Nota-se que o fator de maior impacto é a confiança, que corresponde a um aumento de 5,3\% no índice de eficiência, seguido do relacionamento a longo prazo, que representa um acréscimo de $3,7 \%$, e, por fim, o compartilhamento de informações, que representa um incremento de $1,8 \%$ no índice de eficiência. A capacidade preditiva do modelo é mediana, explicando metade das variações $(49,4 \%)$ e todos os estimadores são relevantes a um nível de $1 \%$ na explicação do índice de eficiência $(\mathrm{p}<0,01)$. 


\section{Conclusões}

Os resultados indicam que há assimetria no relacionamento das empresas pesquisadas, o que pode ser explicado pelo maior poder de barganha por parte das construtoras que conduzem a relação com seus fornecedores no sentido de melhor atender as suas necessidades. Essa assimetria, no entanto, em consonância com os estudos de Bandeira, Mello e Macada (2009) e de Venselaar, Gruis e Verhoeven (2015), não impede a formação de parcerias, inclusive duradouras, afinal o fornecedor, em geral, também se beneficia da relação. A maioria dos fornecedores, por sua vez, mantém com as construtoras um relacionamento adverso e puramente comercial, tal como evidenciado por Beach, Webster e Campbell (2005), tratando-se, portanto, de fornecedores comuns e do tipo I, nas classificações de Merli (1994) e de Lambert, Emmelhainz e Gardner (1996), respectivamente. No que se refere à parceria, esta se encontra no estágio competitivo, segundo a classificação de Li et al. (2001).

O modelo desenvolvido nesta pesquisa explica, por meio da criação de um índice de eficiência composto por três fatores determinantes (confiança, relacionamento de longo prazo e compartilhamento de informações), as características do relacionamento interorganizacional na amostra pesquisada. Serve, portanto, de orientação diretiva para adoção de estratégias de formação de parcerias entre construtoras e fornecedores.

\section{Tabela 5 - Matriz de correlação}

\begin{tabular}{c|r|r|r}
\hline \multicolumn{4}{|c}{ Correlação de Spearman } \\
\hline V & \multicolumn{1}{c|}{ C1 } & \multicolumn{1}{c}{ C2 } & \multicolumn{1}{c}{ C3 } \\
\hline V1 &, 088 &, $305^{-}$ &, $823^{-}$ \\
\hline V2 &, $358^{-}$ &, $305^{-}$ &, $805^{-}$ \\
\hline V3 &, 037 &, $855^{-}$ &, $252^{-}$ \\
\hline V4 &,$- 334^{-}$ &, $641^{-}$ &, $408^{-1}$ \\
\hline V5 &, 191 &, 729 &, 160 \\
\hline V18 &, 730 &,- 060 &, 450 \\
\hline V19 &, $805^{-}$ &, 190 &, 085 \\
\hline V20 &, 789 &, 088 &, 073 \\
\hline C1 & 1,000 &,- 021 &, 025 \\
\hline C2 &,- 021 & 1,000 &, 125 \\
\hline C3 &, 025 &, 125 & 1,000 \\
\hline
\end{tabular}

Tabela 6 - Regressão linear

\begin{tabular}{cl}
\hline \multicolumn{2}{c}{ Regressão Linear } \\
\hline$\delta=\beta_{0}+\beta_{1} C_{1}+\beta_{2} C_{2}+\beta_{3} C_{3}+\epsilon$ \\
\hline Variável Dependente: Coeficiente de Variação $(\delta)$ \\
\hline$\beta_{1}$ & $-0.037^{* * *}$ \\
& $(0.006)$ \\
$\beta_{2}$ & $-0.053^{* * *}$ \\
& $(0.008)$ \\
$\beta_{3}$ & $-0.018^{* * *}$ \\
& $(0.010)$ \\
$\beta_{0}$ & $0.450 * * *$ \\
& $(0.010)$ \\
\hline Observações & 95 \\
\hline$R^{2}$ & 0.510 \\
$R^{2}$ Ajustado & 0.494 \\
Residual Std. Error & $0.096(\mathrm{df}=91)$ \\
Estatística F & $31.542^{* * *}(\mathrm{df}=3 ; 91)$ \\
\hline Notas: & ${ }^{*} \mathrm{p} \leqslant 0.1 ; * * \mathrm{p}=0.05 ; * * * \mathrm{p}=0.01$ \\
\hline
\end{tabular}


Por ordem de importância o fator mais impactante é a confiança, seguido do relacionamento de longo prazo e por fim o compartilhamento de informações. Logo, para a construção e/ou incremento do estágio de parceria deve-se, em um primeiro momento, avaliar/considerar o cumprimento dos acordos interorganizacionais, pois o descumprimento do que foi combinado ou a oposição aos interesses comuns fragilizam a confiança entre as partes (CHEN; PAULRAJ; LADO, 2004). Ao contrário, o estrito cumprimento dos acordos incrementa a confiança, desenvolve a cooperação e mantém hígida a relação entre as partes.

Deve-se, também, formular estratégias, tendo como foco o desenvolvimento/ aprimoramento dos processos seletivos e de avaliação de fornecedores e de promoção de reuniões periódicas com o corpo técnico e o setor de suprimentos da organização. Assim, quanto mais desenvolvidos forem os processos de seleção, avaliação e de reuniões, mais contínuo e longínquo será o relacionamento. $\mathrm{O}$ fator relacionamento de longo prazo é o segundo em importância (geração de impacto) no índice de eficiência da amostra.

Outro fator a considerar no momento da criação da estratégia de parceria é o compartilhamento de informações. Melhor resultado nesse fator depende da comunicação entre as partes, da interligação dos negócios e da integração estrutural. Logo, as estratégias nesse campo devem levar em conta o relacionamento operacional e o grau de envolvimento do fornecedor no ciclo de desenvolvimento do produto da construtora. Importante destacar, também, a realização de reuniões (interatividade), as quais podem ser impulsionadas pela intensificação do compartilhamento de informações (PURDY; SAFAYENI, 2000).

Do que se percebe, para melhorar os índices de eficiência do relacionamento construtorafornecedor, os principais processos que precisam ser considerados quando da criação de estratégias de parcerias são: seleção e avaliação de desempenho de fornecedores e realização de reuniões conjuntas.

Por fim, destaca-se que o modelo proposto pode incorporar novas variáveis e pode ser aplicado a um número maior de empresas do setor da construção civil, o que suscita a iniciativa de outros estudos prospectivos nessa área, servindo, portanto, como sugestão para futuros trabalhos científicos.

\section{Referências}

AKINTOYE, A.; MCINTOSH, G.; FITZGERALD, E. A Survey of Supply Chain Collaboration and Management in the UK Construction Industry. European Journal of Purchasing \& Supply Management, v. 6, p. 159168, 2000.

AZAMBUJA, M.; O'BRIEN, W. J. Construction Supply Chain Modeling: issues and perspectives. In: O’BRIEN, William J.; VRIJHOEF, R.; LONDON, K. A. (Eds.). Construction Supply Chain Management: Handbook. Boca Raton: CRC Press, 2009.

BACHMANN, R. Trust, Power and Control in Trans-Organizational Relations. Organization Studies, v. 22, n. 2, p. 337-365, 2001

BANDEIRA, R. A. de M.; MELLO, L. C. B. de B.; MAÇADA, A. C. G. Relacionamento Interorganizacional na Cadeia de Suprimentos: um estudo de caso na indústria da construção civil. Produção, v. 19, n. 2, p. 376-387, 2009.

BEACH, R.; WEBSTER, M.; CAMPBELL, K. M. An Evaluation of Partnership Development in the Construction Industry. International Journal of Project Management, v. 23, 611-621, 2005.

BLACK, C.; AKINTOYE, A; FITZGERALD, E. An Analysis of Success Factors and Benefits of Partnering in Construction. International Journal of Project Management, v. 18, n. 6, p. 423-434, 2000.

CHENG, E. W. L; LI, H. Construction Partnering Process and Associated Critical Success Factors: quantitative investigation. Journal of management in engineering, v. 18, n. 4, p. 194202, 2002.

CHEN, I. J.; PAULRAJ, A.; LADO, A. A. Strategic Purchasing, Supply Management, and Firm Performance. Journal of Operations Management, v. 22, n. 5, p. 505-523, 2004.

CHEN, W. T.; CHEN, T. Critical Success Factors for Construction Partnering in TAIWAN.

International Journal of Project Management, v. 25, n. 5, p. 475-484, 2007.

CHEUNG, S.-O. et al. Behavioral Aspects in Construction Partnering. International Journal of Project Management, v. 21, n. 5, p. 333-343, 2003.

CHILES, T. H.; MCMACKIN, J. F. Integrating Variable Risk Preferences, Trust, and Transaction Cost Economics. Academy of Management

Review, v. 21, n. 1, p. 73-99, 1996. 
CONSTRUCTION INDUSTRY INSTITUTE. CII: search of partnering excellence. Special publication 17-1. Texas: Construction Industry Institute, 1991.

COOK, E. L.; HANCHER, D. E. Partnering: contracting for the future. Journal of Management in Engineering, v. 6, n. 4, p. 431446, 1990.

DYER, J. H.; OUCHI, W. G. 9 Japanese-Style Partnerships: giving companies a competitive edge. Japanese Business, v. 3, n. 1, p. 200, 1998.

HAIR, JUNIOR, J. et al. Fundamentos de Métodos de Pesquisa em Administração. Porto Alegre: Bookman, 2005.

HELLARD, R. B. Project Partnering: principle and practice. Thomas Telford, 1995.

ISATTO, E. L. Proposição de Um Modelo Teórico-Descritivo Para a Coordenação Interorganizacional de Cadeias de Suprimentos de Empreendimentos de Construção. Porto Alegre, 2005. 305 f. Tese (Doutorado em Engenahria Civil) - Programa de Pós-Graduação em Engenharia Civil, Universidade Federal do Rio Grande do Sul, Porto Alegre, 2005.

JOHNSTON, D. A. et al. Effects of Supplier Trust on Performance of Cooperative Supplier Relationships. Journal of Operations Management, v. 22, n. 1, p. 23-38, 2004.

KUMARASWAMY, M. M..; DISSANAYAKA, S. M. Developing a Decision Support System for Building Project Procurement. Building and Environment, v. 36, n. 3, p. 337-349, 2001.

LAMBERT, D. M.; EMMELHAINZ, M. A.; GARDNER, J. T. Developing and Implementing Supply Chain Partnerships. The International JOURNAL of Logistics Management, v. 7, n. 2, p. 1-18, 1996.

LAZAR, F. D. Project partnering: improving the likelihood of win/win outcomes. Journal of Management in Engineering, v. 16, n. 2, p. 7183,2000 .

LI, H. et al. Co-Operative Benchmarking: a tool for partnering excellence in construction. International Journal of Project Management, v. 19, n. 3, p. 171-179. 2001.

LI, S. et al. Development and Validation of a Measurement Instrument for Studying Supply Chain Management Practices. Journal of Operations Management, v. 23, p. 618-641, 2005.
LI, W. et al. The Impact of Supplier Development on Buyer Competitive Advantage: a path analytic model. International Journal of Production Economics, v. 135, n. 1, p. 353-366, 2012.

LYONS, T. F.; KRACHENBERG, A. R.; HENKE JUNIOR, J. W. Mixed Motive Marriages: what's next for buyer-supplier relations? MIT Sloan Management Review, v. 31, n. 3, p. 29, 1990.

MERLI, G. Comakership: a nova estratégia para os suprimentos. Rio de Janeiro: Qualitymark, 1994.

NG, S. T. et al. Problematic Issues Associated With Project Partnering: the contractor perspective. International Journal of Project Management, v. 20, n.6, p. 437-449, 2002.

OJALA, M.; HALLIKAS, J. Investment DecisionMaking in Supplier Networks: management of risk. International Journal of Production Economics, v. 104, n. 1, p. 201-213, 2006.

PURDY, L.; SAFAYENI, F. Strategies for Supplier Evaluation: a framework for potential advantages and limitations. IEEE Transactionson Engineering Management, v. 47, n. 4, p. 435443, 2000.

SANTOS, A. de P. L.; JUNGLES, A. E. Como Gerenciar as Compras de Materiais na Construção Civil. São Paulo: Pini, 2008.

SCOTT, B. Partnering in Europe: incentive based alliancing for projects. Thomas Telford, 2001.

SELNES, F. Antecedents and Consequences of Trust and Satisfaction in Buyer-Seller Relationships. European Journalof Marketing, v. 32, n. 3/4, p. 305-322, 1998.

SUH, T.; KWON, I.-W. G. Matter Over Mind: when specific asset investment affects calculative trust in supply chain partnership. Industrial Marketing Management, v. 35, n. 2, p. 191-201, 2006.

TANG, W.; DUFFIELD, C. F.; YOUNG, D. M. Partnering Mechanism in Construction: an empirical study on the Chinese construction industry. Journal of Construction Engineering and Management, v. 132, n. 3, p. 217-229, 2006.

TUTEN, T. L.; URBAN, D. J. An Expanded Model of Business-to-Business Partnership Formation and Success. Industrial Marketing Management, v. 30, n. 2, p. 149-164, 2001. 
VENSELAAR, M.; GRUIS, V.; VERHOEVEN, F. Implementing Supply Chain Partnering in the Construction Industry: work floor experiences within a Dutch housing association. Journal of Purchasing and Supply Management, v. 21, n. 1 , p. 1-8, 2015.
VRIJHOEF, R.; KOSKELA, L. The Four Roles of Supply Chain Management in Construction. European Journal of Purchasing \& Supply Management, v. 6, n. 3, p. 169-178, 2000.

Christiane Wagner Mainardes Krainer Programa de Pós-Graduação em Engenharia Civil | Universidade Tecnológica Federal do Paraná | Rua Deputado Heitor Alencar Furtado, 5.000, Campo Comprido | Curitiba - PR - Brasil | CEP 81280-340 | Tel.: (41) 3279-4500 | E-mail: chriswmk70@gmail.com

\section{Jefferson Augusto Krainer}

Programa de Pós-Graduação em Engenharia Civil | Universidade Tecnológica Federal do Paraná | E-mail: profjeffersonkra@gmail.com

\section{Ricardo Cataldi}

Programa de Pós-Graduação em Economia | Universidade Federal do Rio Grande do Sul | Av. João Pessoa, 52, Sala 33B - $3^{\circ}$ andar, Centro Histórico | Porto Alegre - RS - Brasil | CEP 90040-000 | Tel.: (51) 3308-4050 | E-mail: cataldi.ricardo@gmail.com

Alfredo larozinski Neto

Programa de Pós-Graduação em Engenharia Civil | Universidade Tecnológica Federal do Paraná | E-mail: alfredo.iarozinski@gmail.com

Cezar Augusto Romano

Programa de Pós-Graduação em Engenharia Civil | Universidade Tecnológica Federal do Paraná | E-mail: romano.utfpr@gmail.com

Revista Ambiente Construído

Associação Nacional de Tecnologia do Ambiente Construído

Av. Osvaldo Aranha, $99-3^{\circ}$ andar, Centro

Porto Alegre - RS - Brasil

CEP $90035-190$

Telefone: +55 (51) 3308-4084

Fax: +55 (51) 3308-4054

www.seer.ufrgs.br/ambienteconstruido

E-mail: ambienteconstruido@ufrgs.br 